\title{
Reducing Abrasive Particle Generation in Dry Rotary Swaging by Utilizing DLC Hard Coated Dies
}

\author{
Florian Böhmermann ${ }^{1, *}$, Marius Herrmann ${ }^{2}$, Oltmann Riemer ${ }^{1}$, and Bernd Kuhfuss ${ }^{2,3}$ \\ ${ }^{1}$ IWT Leibniz Institute for Materials Engineering, Laboratory for Precision Machining, Badgasteiner Straße 3, 28359 Bremen, Germany \\ ${ }^{2}$ bime Bremen Institute for Mechanical Engineering, University of Bremen, Badgasteiner Straße 1, 28359 Bremen, Germany \\ ${ }^{3}$ MAPEX Center for Materials and Processing, University of Bremen, Am Fallturm 1, 28359, Bremen, Germany
}

\begin{abstract}
The emphasis of this paper is the investigation of the impact of the diamond like carbon (DLC) hard coating system on the amount of abrasive particles being generated during dry rotary swaging. Rotary swaging experiments applying coated and uncoated macro structured forming dies were carried out against aluminum and steel work pieces varying the process parameter feed velocity. It was found that DLC coatings effectively reduce the generation of abrasive particles from the work piece. For dry machining of aluminum the amount was reduced to a tenth of the original quantity achieved with uncoated dies. The results are discussed with regard to the mechanics of interfacing surfaces. Additionally, forming dies exhibiting macro structures surfaces of improved design were introduced and applied in dry rotary swaging experiments, which allowed minimizing the abrasive particle generation.
\end{abstract}

Keyword: Sustainable machining, Cold forming, Die

\section{Introduction}

Rotary swaging is an incremental bulk metal forming process for the manufacture of rotational symmetric lightweight components, e.g. axles and steering spindles. Compared to those machined by cutting, work pieces machined by rotary swaging exhibit advantageous material properties. These properties are a result of strain hardening and an undisturbed material fiber flow. Besides, rotary swaging allows for an optimal use of material resources through the flexible adaption of wall thicknesses of work pieces. Common for bulk metal forming processes, rotary swaging is associated with high pressures per unit area and high process forces. A robust process layout mandatorily requires for the adequate lubrication of forming dies and work pieces [1]. Functions of the lubricant are mainly the avoidance of abrasive die wear when machining steel, the avoidance of adhesive die wear when machining aluminum, the provision of work piece's surface finish and dimensional accuracy, and at last the purging of particles abraded from the work pieces out of the swaging unit. Recent scientific research dealt with the development of a dry rotary swaging process layout. Functionalized rotary swaging dies were introduced, exhibiting both hard coated and structured surfaces to encounter complex and opposing tribological requirements [2]. Tungsten doped amorphous diamond like carbon coatings $(\mathrm{a}-\mathrm{C}: \mathrm{H}: \mathrm{W})$ with additional a-C:H top layer characterized by excellent hardness and fracture toughness were applied to forming dies for friction reduction and wear protection [3, 4].
Furthermore, macro structured reduction zones of forming dies were used to control the axial reaction force that counteracts the feed force. The features, here, were sine wave structures with propagation parallel to the feed direction, amplitudes of several tenths of micrometers, and wave lengths of about one millimeter [5, 2]. It should be noticed, that structured reduction zones are necessary, as obligatory friction increasing rough layers from tungsten carbide as applied to conventional rotary swaging dies, cannot be used in dry rotary swaging due to immediate clogging. The principles of this new approach are sketched in Figure 1.

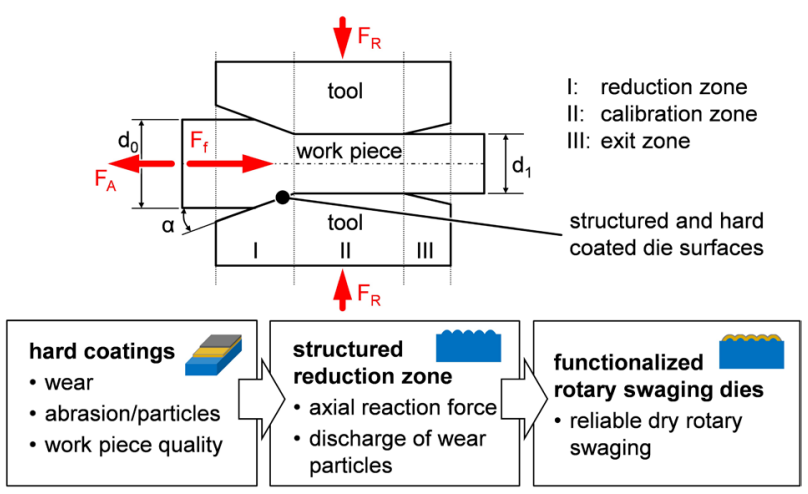

Fig. 1. Principles of infeed rotary swaging displayed in crosssectional view and approaches for a dry process layout (in accordance with [6]).

The conduction of first dry rotary swaging experiments was shown in multiple studies. Solely DLC coated rotary swaging dies allowed for the successful 
machining of aluminum 3.3206 tubes. The coating suppressed adhesion of aluminum on the dies' surfaces while providing good surface finish of the work pieces, similar to conventional, lubricated rotary swaging [7]. Forming dies exhibiting sine wave structures (amplitude $\mathrm{A}=0.05 \mathrm{~mm}$, wavelength $\lambda=1.3 \mathrm{~mm}$ ) were applied to the machining of tubes from 1.0038 construction steel. In comparison to unstructured rotary swaging dies, the dies' design reduced the tracking error of the feed system associated with the axial reaction force $\mathrm{F}_{\mathrm{A}}$ by $50 \%$ for dry machining and up to $400 \%$ when machining under lubricated conditions [8]. Furthermore, such structured forming dies with additional tungsten doped amorphous diamond like carbon coating (a-C:H:W) plus a-C:H top layer were tested against steel tubes. Successful dry rotary swaging was achieved with maintainable defects of the hard coating under given harsh conditions [7]. However, dry rotary swaging with functionalized forming dies is subject to an increased abrasive particle generation from the work piece material and accumulation of such particles in the forming zone, associated with a loss in work piece quality and a clogging of the swaging unit. The generation of abrasive particles was explained with the particular contact conditions of sine wave structured dies and the work piece. Induced local strain in the work pieces lead to a local embrittlement of the surface near material and ultimately to the detachment of tinsels from the work pieces' surfaces [6].

The emphasis of this work is the investigation of the impact of the diamond like carbon (DLC) hard coating system on the amount of abrasive particles generated in dry rotary swaging with forming dies. Dry rotary swaging experiments are conducted with uncoated and coated surfaces varying the material machined and the feed velocity. Abrasive particles are collected and investigated by means of optical microscopy. Furthermore, functionalized forming dies of improved macros structure design are presented and applied to dry rotary swaging experiments. Results of the presented work are of major concern for the development of robust rotary swaging processes under dry conditions.

\section{Experiments}

All dry rotary swaging experiments were carried out on a Felss HE-32 machine tool with a four die swaging unit setup. The swaging frequency is depending on the rotational speed of the swaging unit and was set to $37.5 \mathrm{~Hz}$. The stroke height $h_{t}$ of the dies was $1 \mathrm{~mm}$. The machine tool is equipped with a linear direct driven feed unit for axial work piece feed, able to generate a maximum feed force $F_{f}$ of $20 \mathrm{kN}$.

Two sets of functionalized rotary swaging dies were applied in the experiments. These die sets were both of the same geometry, but one set additionally exhibited hard coated surfaces. The bulk material of the dies was 1.2379 hardened tool steel with a hardness of $62 \pm 0.6 \mathrm{HRC}$. The dies exhibited a die angle of $\alpha=10^{\circ}$ and allow for the diameter reduction of rods and hollow shafts from $\mathrm{d}_{0}=20 \mathrm{~mm}$ down to $\mathrm{d}_{1}=15 \mathrm{~mm}$. The reduction zone of the dies exhibited a sine wave structure with an amplitude of $\mathrm{A}=0.05 \mathrm{~mm}$ and a wavelength of $\lambda=1.3 \mathrm{~mm}$ for the control of the axial reaction force $\mathrm{F}_{\mathrm{A}}$. The uncoated set of forming dies hereafter is notated " $\mathrm{S}$ " for structured. Physical vapor deposition (PVD) was used for coating the second set of dies (hereafter notated: "SC" for structured and coated). The hard coating system was a $\mathrm{Cr} / \mathrm{CrN} / \mathrm{Cr}+\mathrm{WC} / \mathrm{a}-\mathrm{C}: \mathrm{H}: \mathrm{W}$ multilayer system with additional a-C:H top layer.

Two different types of work pieces were applied to the machining experiments: Aluminum 3.3206 (AlMgSi0.5) tubes and 1.0038 construction steel tubes. All work pieces were of the same geometry: initial length $\mathrm{l}_{0}=300 \mathrm{~mm}$, initial diameter $\mathrm{d}_{0}=20 \mathrm{~mm}$, and initial wall thickness $\mathrm{s}_{0}=2 \mathrm{~mm}$.

The general experimental procedure comprising of the actual dry rotary swaging as well as the methodology of abrasive particle collection and analysis was introduced before in [8]. This procedure is adopted for the presented work, but for the sake of completeness will hereinafter again be explained in detail. The experimental procedure comprises of the dry rotary swaging of two work pieces in a row and subsequently the disassembly of the four rotary swaging dies from the swaging unit, investigation of the dies, and collection of abrasive particles. For each set of dies and work piece material experiments were conducted at two feed velocities: $\mathrm{v}_{\mathrm{f}}=500 \mathrm{~mm} / \mathrm{min}$ and $\mathrm{v}_{\mathrm{f}}=2000 \mathrm{~mm} / \mathrm{min}$; the first is considered a moderate feed velocity for infeed rotary swaging, while the latter is considered an advanced feed velocity. This summed up to an overall number of experiments of eight and the machining of 16 work pieces. In preparation for every new experiment the forming dies were thoroughly cleaned by rinsing and wiping using ethanol. After the experiments the dies were visually inspected. Particles were first collected from the reduction zone and the calibration zone from each of the four forming dies. Here, actual contact of dies' and work piece's surfaces occur when rotary swaging. The particles were rinsed into Petri dishes for later investigation using acetone. Particles adhering to the tapered rotary swaging dies' flanks were collected by carefully removing those using a brush, compare Figure 2.

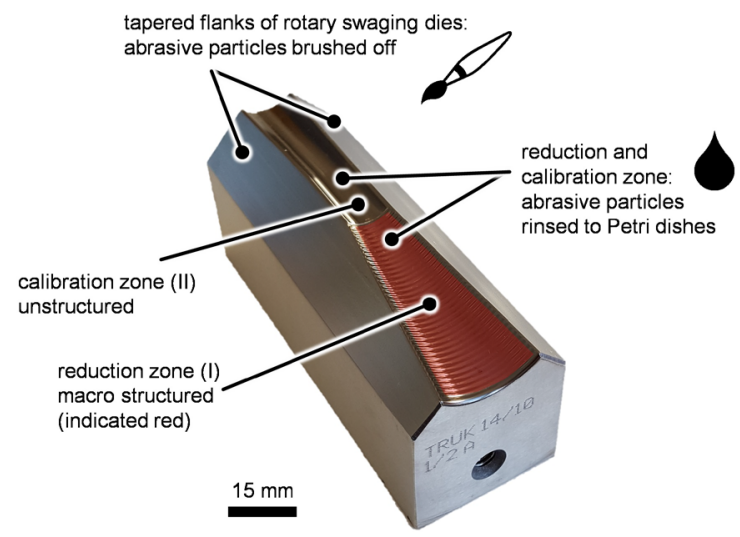

Fig. 2. Functionalized rotary swaging die exhibiting a sine wave structured reduction zone and indication of abrasive particle collection procedure. 
The particle analysis was carried out using a Sensofar Plu 2300 optical profilometer in microscope operation mode. The maximum particle areal expanses $A_{\max }$ in square millimeter were derived for each the samples taken from the reduction and calibration zone, and from the tapered flanks, respectively. Furthermore, a comparative analysis of the amount of abrasive particles generated in the various experiments was conducted. For this purpose, the categories $\mathrm{A}$ to $\mathrm{J}$ for the assessment of the amount of abrasive particles are introduced, where A is attributed to the minimum amount of particles over all 12 experiments and $\mathrm{J}$ attributed to the maximum amount of particles. This analysis is solely qualitative. Within limits, it allows for the derivation of trends regarding the abrasive particle generation when rotary swaging in dependence of the work piece material and the feed velocity, but is accompanied with a comparably high uncertainty.

\section{Results}

Distinct abrasive particle generation was found for the experiments applying the uncoated forming dies "S". The amount and the characteristics of particles strongly differed with the machined material. After the machining of aluminum tubes excessive amounts of aluminum flakes were found. In the context of this work particles referred to as flakes are of planar shape and comparably high rigidity, where the rigidity is determined by the particles' thickness. Their overall amount strongly depends on the feed velocity. In contrast, when machining steel the feed velocity of the experiment had barely any impact on the amount and the size of abrasive particles generated. Besides steel abrasive particles were of finer structure and should be referred to as tinsels. Tinsels are as well of planar shape but less rigid, what indicates lower particle thicknesses. The results of the

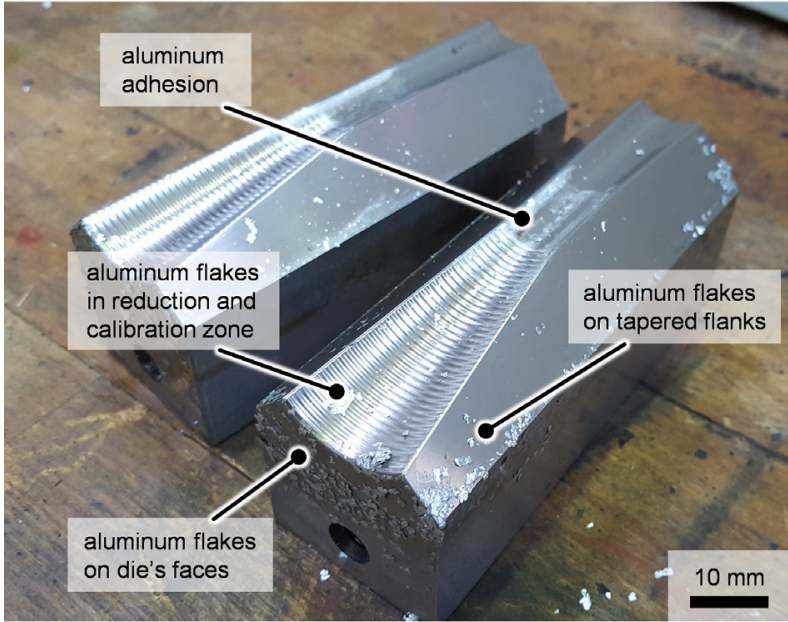

Fig. 3. Uncoated rotary swaging dies "S" after die machining of aluminum 3.3206 work pieces $\left(\mathrm{v}_{\mathrm{f}}=500 \mathrm{~mm} / \mathrm{min}\right)$ exhibiting aluminum flakes and aluminum adhesion in the reduction and calibration zone.

optical abrasive particle analyses for all experiments are given in Table 1.

Figure 3 shows an uncoated rotary swaging die after the machining of aluminum 3.3206 work pieces. Representative for results of all experiments applying this particular work piece and forming die combination, the die is distinctively covered with flakes from aluminum abraded form the work pieces in the reduction and calibration zone, the tapered flanks, and additionallyon the faces of the forming dies. Those flakes can be characterized as of medium expanse about five to $20 \mathrm{~mm}^{2}$ - and as relatively rigid. Besides distinctive aluminum adhesion was found in the reduction and the calibration zone of the dies. Whilst the particle expanse remained nearly unchanged, the overall amount of particles strongly increased towards the higher feed velocity of $2000 \mathrm{~mm} / \mathrm{min}$. The amount of

Table 1. Results of particle analyses in dependence on the applied forming dies, the work piece material, and the feed velocity.

\begin{tabular}{|c|c|c|c|c|c|c|}
\hline \multirow[b]{2}{*}{$\begin{array}{l}\text { forming die } \\
\text { type }\end{array}$} & \multirow[b]{2}{*}{$\begin{array}{l}\text { work piece } \\
\text { material }\end{array}$} & \multirow[b]{2}{*}{$\begin{array}{l}\text { feed velocity } \\
\qquad v_{\mathrm{f}} \\
\mathrm{mm} / \mathrm{min}\end{array}$} & \multicolumn{2}{|c|}{$\begin{array}{l}\text { particles collected from reduction } \\
\text { and calibration zone }\end{array}$} & \multicolumn{2}{|c|}{$\begin{array}{l}\text { particles collected from the } \\
\text { tapered flanks of the dies }\end{array}$} \\
\hline & & & $\begin{array}{l}\text { areal expanse } \\
\qquad \begin{array}{c}\mathrm{A}_{\max } \\
\mathrm{mm}^{2}\end{array}\end{array}$ & $\begin{array}{c}\text { amount category } \\
- \\
-\end{array}$ & $\begin{array}{l}\text { areal expanse } \\
\qquad \begin{array}{c}\mathrm{A}_{\max } \\
\mathrm{mm}^{2}\end{array}\end{array}$ & $\begin{array}{c}\text { amount category } \\
- \\
-\end{array}$ \\
\hline \multirow{4}{*}{$\begin{array}{l}\text { uncoated } \\
\text { forming dies } \\
\text { "S" }\end{array}$} & \multirow{2}{*}{$\begin{array}{l}\text { aluminum } \\
3.3206\end{array}$} & 500 & $7.8^{*}$ & $\mathrm{H}$ & $10.0^{*}$ & I \\
\hline & & 2000 & $14.7^{*}$ & $\mathrm{~J}$ & $16.5^{*}$ & $\mathrm{~J}$ \\
\hline & \multirow{2}{*}{ steel 1.0038} & 500 & 4.9 & $\mathrm{C}$ & 5.0 & G \\
\hline & & 2000 & 9.2 & $\mathrm{C}$ & 11.0 & G \\
\hline \multirow{4}{*}{$\begin{array}{l}\text { hard coated } \\
\text { forming dies } \\
\text { "SC" }\end{array}$} & \multirow{2}{*}{$\begin{array}{c}\text { aluminum } \\
3.3206\end{array}$} & 500 & 1.2 & A & 27.7 & A \\
\hline & & 2000 & 7.0 & $\mathrm{E}$ & 234.3 & $\mathrm{C}$ \\
\hline & \multirow{2}{*}{ steel 1.0038} & 500 & 3.5 & $\mathrm{C}$ & 3.0 & $\mathrm{C}$ \\
\hline & & 2000 & 1.3 & $\mathrm{C}$ & 4.4 & B \\
\hline \multirow{4}{*}{$\begin{array}{c}\text { novel design } \\
\text { "nSC" }\end{array}$} & \multirow{2}{*}{$\begin{array}{c}\text { aluminum } \\
3.3206\end{array}$} & 500 & 0.6 & A & 0.2 & A \\
\hline & & 2000 & 0.5 & A & 7.2 & A \\
\hline & \multirow{2}{*}{ steel 1.0038} & 500 & 0.4 & B & 0.1 & A \\
\hline & & 2000 & 0.6 & $\mathrm{~B}$ & 0.2 & A \\
\hline
\end{tabular}

*Abrasive particles characterized as rigid flakes. 
particles found here was the largest throughout all experiments carried out in this work and consequently assigned to the amount category $J$. The number of particles generated was more than double than those generated when machining with the moderate feed velocity of $500 \mathrm{~mm} / \mathrm{min}$ (amount category $\mathrm{H}$ ), compare Figure 4. Strong aluminum adhesion was found in the reduction and calibration zones of the forming dies.
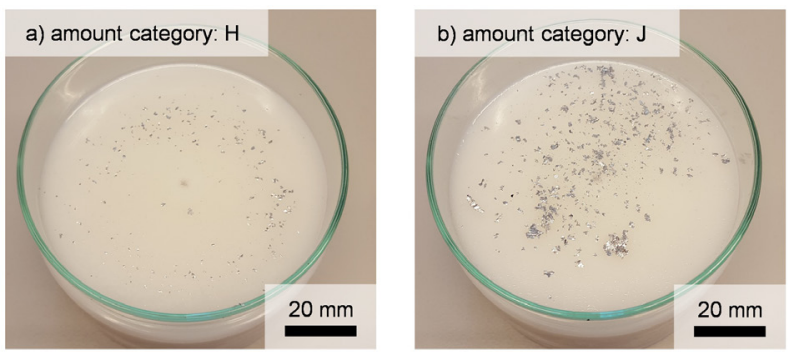

Fig. 4. Petri dish with abrasive particles from aluminum 3.3206 rinsed from the reduction and calibration zone of the uncoated forming dies "S" after the experiments with a) $v f=500 \mathrm{~mm} / \mathrm{min}$ and b) $v f=2000 \mathrm{~mm} / \mathrm{min}$.

Abrasive particles of relatively small expanse were found on both the reduction and calibration zone and the tapered flanks of the uncoated forming dies after the machining of work pieces from 1.0038 construction steel. The maximum expanse of a single particle was $\mathrm{A}_{\max }=11.0 \mathrm{~mm}^{2}$ generated during the machining with a feed velocity of $v_{f}=2000 \mathrm{~mm} / \mathrm{min}$. However, a significant influence of the selected feed velocity on the amount or the expanse of abrasive particles cannot be determined form the experiments, compare Figure 5. Generally, particles found for the particular combination of uncoated forming dies and steel work pieces are less rigid compared to those generated during the machining of aluminum and, here, were characterized as tinsels.
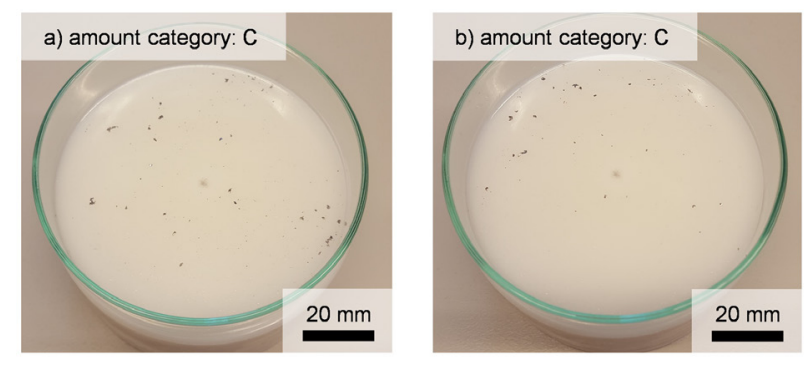

Fig. 5. Petri dishes with abrasive particles from steel 1.0038 rinsed from the reduction and calibration zone of the uncoated forming dies "S" after the experiments with a) $\mathrm{v}_{\mathrm{f}}=500 \mathrm{~mm} / \mathrm{min}$ and b) $\mathrm{v}_{\mathrm{f}}=2000 \mathrm{~mm} / \mathrm{min}$.

The experiments applying the structured and coated forming dies "SC" were also subject to distinct abrasive particle generation from the work pieces. The expanse, the amount, and characteristics of such particles were primarily determined by the work piece material, while the influence of the feed velocity on the particle generation is of second order. Only when machining aluminum work pieces a more distinct dependency of the particle size on the feed velocity was found, reflecting those results gained from the machining with uncoated dies. Most important to notice is the capability of the hard coating system on the forming dies to effectively reduce the amount of abrasive particles generated when machining 3.3206 aluminum work pieces to about a tenth of the original value indicated by the amount categories. The results of the experiments regarding the abrasive particle analyses are given in Table 1.

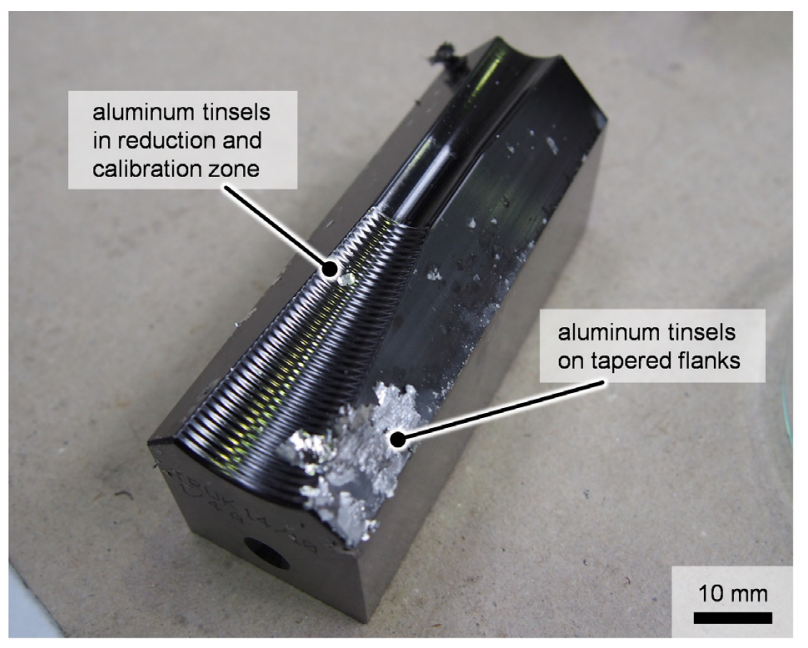

Fig. 6. Coated rotary swaging die "SC" after die machining of aluminum 3.3206 work pieces $\left(\mathrm{v}_{\mathrm{f}}=500 \mathrm{~mm} / \mathrm{min}\right)$ exhibiting aluminum tinsels of comparably great areal expanse on its tapered flanks.
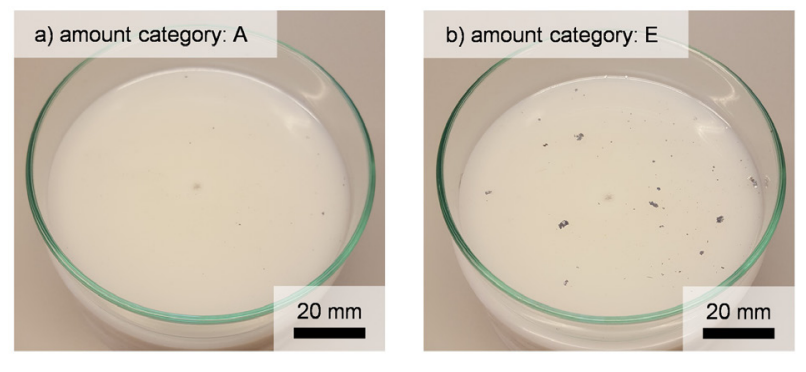

Fig. 7. Petri dishes with abrasive particles from aluminum 3.3206 rinsed from the reduction and calibration zone of the coated forming dies "SC" after the experiments with a) $\mathrm{v}_{\mathrm{f}}=500 \mathrm{~mm} / \mathrm{min}$ and b) $\mathrm{v}_{\mathrm{f}}=2000 \mathrm{~mm} / \mathrm{min}$.

In Figure 6 one of the four rotary swaging dies after the machining of aluminum 3.3206 tubes is displayed. Representative for all four experiments machining aluminum and varying the feed velocity, the forming dies exhibit abrasive particles of greater areal expanse on the tapered flanks. These particles, other than those generated during the machining of aluminum work pieces with uncoated tools, were of relative fine structure and should be characterized as tinsels. The increase of the feed velocity to $v_{f}=2000 \mathrm{~mm} / \mathrm{min}$ resulted in a strong increase of the amount and the areal expanse of those particles. The largest tinsel had an areal expanse of $A_{\max }=234.3 \mathrm{~mm}^{2}$. In comparison, the reduction zone and the calibration zone were free of larger tinsels and exhibited comparably low numbers of abrasive particles. This is reflected in the small amount of particles rinsed into the Petri dishes after the experiments; compare Figure 7. It is expected that the majority of the abrasive particles generated while forming is pushed in the gaps 
between the forming dies and compressed to tinsels of greater areal expanse at the tapered flanks when the dies repetitively come into contact at every incremental forming operation. The primary particle areal expanse generated from the work piece may not exceed $\mathrm{A}_{\max }=7.0 \mathrm{~mm}^{2}$ for the machining of aluminum 3.3206 tubes.

For all rotary swaging experiments machining 1.0038 construction steel work pieces the rotary swaging dies exhibited greater amounts of tinsels with smaller areal expanse on their tapered flanks after machining; compare Figure 8).

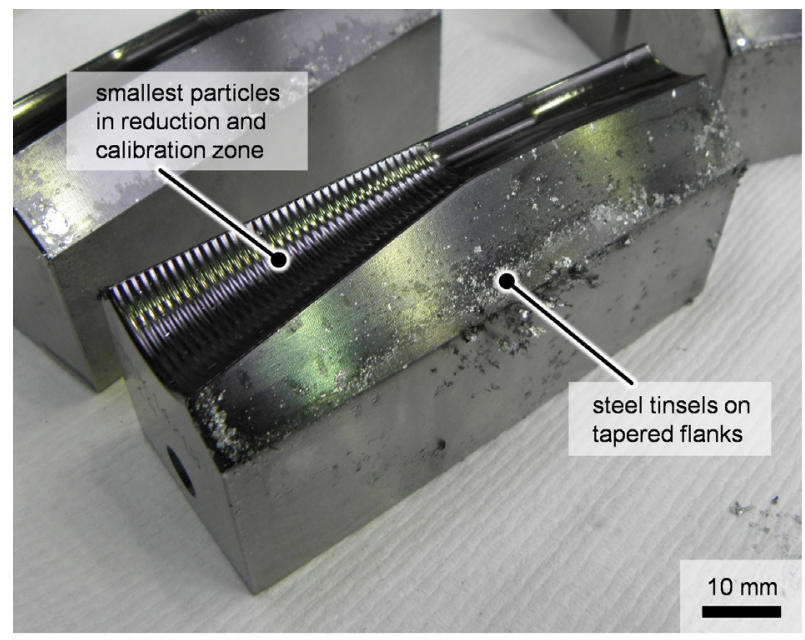

Fig. 8. Coated rotary swaging die "SC" after die machining of 1.00038 work pieces $\left(\mathrm{v}_{\mathrm{f}}=500 \mathrm{~mm} / \mathrm{min}\right)$ exhibiting distinct amounts of tinsels of smaller areal expanse on its tapered flanks.

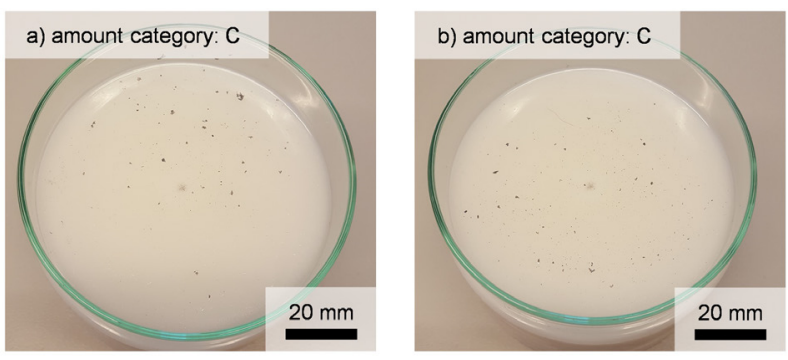

Fig. 9. Petri dishes with abrasive particles from steel 1.0038 rinsed from the reduction and calibration zone of the coated forming dies "SC" after the experiments with a) $\mathrm{v}_{\mathrm{f}}=500 \mathrm{~mm} / \mathrm{min}$ and b) $\mathrm{v}_{\mathrm{f}}=2000 \mathrm{~mm} / \mathrm{min}$.

Independent from the chosen feed velocity, the abrasive particles found on both, the tapered flanks and in the reduction and calibration zone, exhibited almost the same maximum areal expanse $\mathrm{A}_{\max }$ in a range from $1.3 \mathrm{~mm}^{2}$ to $4.4 \mathrm{~mm}^{2}$. The tinsels at the tapered flanks, as in the other experiments, are expected to be formed by the incremental forming operation, after being pushed in the gaps between the rotary swaging dies. However, far smaller tinsels were found compared to the experiments machining aluminum work pieces with the coated forming dies. Small tinsels were rinsed from the reduction and the calibration zone into the Petri dishes for optical inspection after the experiments machining 1.0038 steel tubes, compare Figure 9. These were assigned to the amount category $\mathrm{C}$ for both the feed velocities $500 \mathrm{~mm} / \mathrm{min}$ and $2000 \mathrm{~mm} / \mathrm{min}$, respectively. The maximum areal expanse of these particles did not exceed $3.5 \mathrm{~mm}^{2}$ for any of the applied feed velocities

\section{Discussion}

Dry rotary swaging is generally associated with an increased generation of abrasive particles form the work piece material. The phenomenon was observed for all conducted experiments, independent from the machined work piece material. The most distinct particle generation was observed for the machining of aluminum tubes with uncoated forming dies at increased feed velocities. The amount of particles found after the experiment was about ten times of those found for the machining with hard coated rotary swaging dies.

The abrasive particle generation in dry rotary swaging is traced back to the particular contact conditions of sine wave structured reduction zone and the work piece during the forming process. Here, alternating local strain and compression of the surface near work piece material layer occurs. Local strain occurs once the material is pressed into a valley of the sine wave structure, local compression when the material is pressed onto a peak of the sine wave structure. Local strain and compression result in a distinct strain hardening of the surface near work piece material layer accompanied with ongoing local embrittlement. This finally leads to the failure of the surface near material layer and with that the detachment of abrasive particles from the work piece's surface. The explained mechanism of particle generation is supported by the findings from finite element method (FEM) simulations, investigating stress states in the work piece material emerging while rotary swaging with sine wave structured rotary swaging dies [9]. The abrasive particles generated in the experiments can be characterized as fine tinsels, except the case of machining of aluminum work pieces with uncoated forming dies. Besides different characteristics of generated abrasive particles - these were flakes of relatively rigid structure - the amount of generated particles increased tenfold at a feed velocity of $\mathrm{v}_{\mathrm{f}}=2000 \mathrm{~mm} / \mathrm{min}$. Here, an additional mechanism of particle generation must be taken into account. Besides the local stain occurring while the work piece material is pressed into the sine wave structure, the adhesion between the work piece and the forming dies plays a major role. During the deformation of the work piece new surface layers on the aluminum work piece are generated, which are free of protective oxide layers. These new surfaces are able to chemically bond, or adhere, to the steel surfaces of the forming dies. The breakup of these to cold welds requires for considerably increased shearing of the work piece material during the forming process, intensifying its local embrittlement and such the detachment of abrasive particles. The findings are underlined by the presence of aluminum adhesive layers in the reduction and the calibration zone of the uncoated rotary swaging dies after the experiments. It can be concluded that dry rotary swaging of aluminum 
work pieces with uncoated forming dies is not feasible. Besides, the experimental results impressively underline the capability of the a-C:H:W/a-C:H hard coated dies to effectively suppress adhesion. In direct comparison to the experiments applying uncoated dies, the number of particles generated was cut by ten when machining aluminum 3.3206 work pieces.

For all experiments the largest amount of abrasive particles from the work piece material was found on the tapered flanks of the rotary swaging dies. Particles predominantly generated in the reduction zone are subsequently pressed into the gaps between the forming dies and are formed to tinsels of greater areal expanse by the incremental forming strokes. Exceptions were the result of the experiments forming aluminum work pieces with uncoated forming dies. The here generated particles generated were more rigid. Contact pressures between dies were not enough to deform particles sufficiently in order to generate tinsels; the particles maintained their original areal expanse of about $A_{\max }=15 \mathrm{~mm}^{2}$. The revolving motion of the swaging unit is expected to facilitate the phenomenon of pressing particles into the gaps between forming dies. For ongoing machining the buildup of greater amounts of work piece material in the gaps is expected. This ultimately hinders the complete closing of the dies whilst the die stroke and leads to geometrical inaccuracy of the machined work pieces and a significant earlier termination of the forming process. A robust dry rotary swaging cannot be achieved for the given conditions and requires for a further development of the rotary swaging dies' design.

An enhanced design of the rotary swaging dies must encounter both, the reduction of abrasive particle generation and measures preventing particles to be pressed into the gaps between the dies and their agglomeration on the tapered flanks; compare Figure 10. A reduced particle generation can be achieved by a redesign of the sine wave structures in the dies' reduction

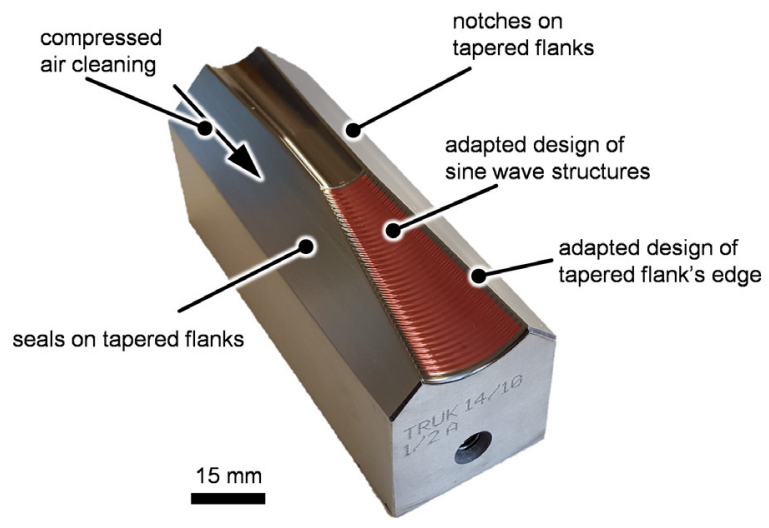

Fig. 10. Improvements of dies' design reducing abrasive particle generation and abrasive particle agglomeration on the tapered flanks in dry rotary swaging.

zone. Sine wave structures with fading, amplitude towards the calibration zone are a possible compromise between control of process forces and minimizing the generation of abrasive particles. Besides, this particular structure design can help improving the surface finish of the machined work pieces. An adaption of the edge between reduction and calibration zone and the tapered flanks could additionally help reducing the amount of particles pressed in the gaps between the rotary swaging dies. Particles still able to enter the gaps between the dies should be entrapped in notches on the tapered flanks. Thus, a buildup of greater amounts of abrasive particles on the tapered flanks can effectively be avoided. A cleaning system utilizing compressed air could be applied to blow particles out from the notches and out of the swaging unit. Additional seals alongside the tapered flanks shall avoid abrasive particles to penetrate deeper into the mechanics of the swaging unit. The presented changes in the forming dies should consequently allow for a robust dry rotary swaging process layout.

\section{Improved dies' design}

Based on the findings from the experiments presented in the sections above, functionalized forming dies of improved design were developed, encountering a redesign of the macro structures applied to their reduction zone. These novel forming dies hereafter should be notated "nSC" for novel, structured, and coated. Other than the primary forming dies with a sine wave structure of constant amplitude $(\mathrm{A}=0.05 \mathrm{~mm})$ applied to the reduction zone, newly developed dies exhibit a sine wave structure, with fading amplitude towards the calibration zone. Starting from a maximum amplitude of again $\mathrm{A}=0.05 \mathrm{~mm}$, the structure's height decreased to $A=0 \mathrm{~mm}$ over a distance of $\mathrm{s}=10.4 \mathrm{~mm}$ until reaching the transition between deduction and calibration zone (unified amplitude decrease about $5 \mu \mathrm{m} / \mathrm{mm}$ ), compare Figure 11 . The wavelength $\lambda$ of the sine wave structure and the forming die angle $\alpha$ were kept unchanged at $1.3 \mathrm{~mm}$ and $10^{\circ}$, respectively. The set of improved forming dies again was made from 1.2379 hardened tool steel with a hardness of $62 \pm 0.6 \mathrm{HRC}$. Besides, the novel rotary swaging dies were hard coated with the well-established $\mathrm{Cr} / \mathrm{CrN} / \mathrm{Cr}+\mathrm{WC} / \mathrm{a}-\mathrm{C}: \mathrm{H}: \mathrm{W}$ multilayer system with a-C:H top layer. Such functionalized rotary swaging dies of improved design were first introduced by Hermann et al. [10].

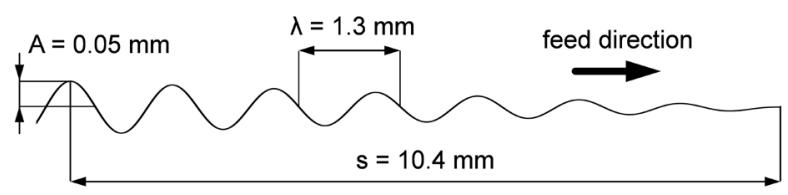

Fig. 11. Cross-sectional sketch of the fading sine wave macro structure applied to the reduction zone of the novel functionalized forming dies nSC (illustration not to scale).

The novel dies were applied to the same experimental procedure as explained above for abrasive particle generation assessment in dry rotary swaging. Again, work pieces from 3.3206 aluminum alloy and 1.0038 construction steel were applied. The feed velocities in the dry rotary swaging experiments were $500 \mathrm{~mm} / \mathrm{min}$ and $2000 \mathrm{~mm} / \mathrm{min}$, respectively. 


\section{Results: Improved dies}

Only lowest amounts of abrasive particles were found for the experiments applying the novel forming dies with redesigned reduction zone and DLC hard coated surfaces "nSC". The results of the abrasive particle analyses after experiments are given in Table 1. Furthermore, the Petri dishes containing the abrasive particles rinsed from the reduction and the calibration zones are displayed in Figure 12 and Figure 13.
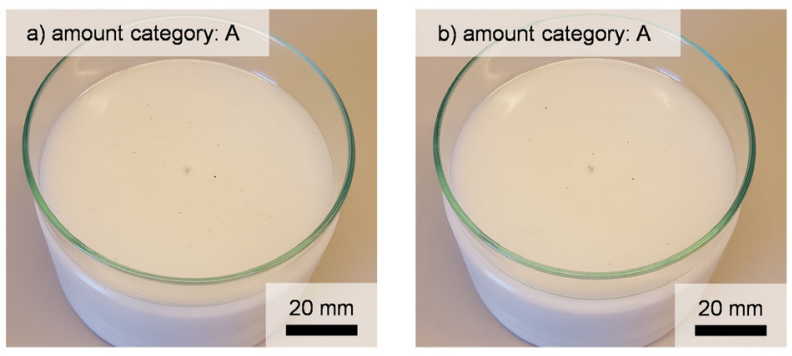

Fig. 12. Petri dishes with abrasive particles from aluminum 3.3206 rinsed from the reduction and calibration zone of the novel functionalized forming " $\mathrm{nSC}$ " dies after the experiments with a) $\mathrm{v}_{\mathrm{f}}=500 \mathrm{~mm} / \mathrm{min}$ and b) $\mathrm{v}_{\mathrm{f}}=2000 \mathrm{~mm} / \mathrm{min}$.
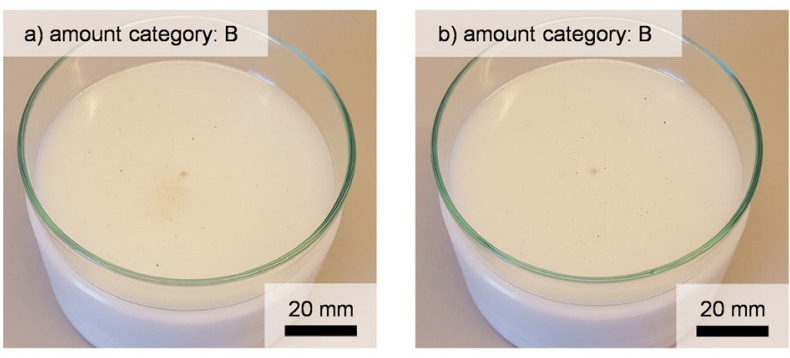

Fig. 13. Petri dishes with abrasive particles from steel 1.0038 rinsed from the reduction and calibration zone of the novel functionalized forming dies "nSC" after the experiments with a) $\mathrm{v}_{\mathrm{f}}=500 \mathrm{~mm} / \mathrm{min}$ and b) $\mathrm{v}_{\mathrm{f}}=2000 \mathrm{~mm} / \mathrm{min}$.

The expanse of particles found usually did not exceeded $\mathrm{A}_{\max }=0.6 \mathrm{~mm}^{2}$, the amount of particles found did not exceeded category $\mathrm{B}$, neither for the machining of aluminum nor for 1.0038 steel work pieces. Only after the machining of aluminum tubes at the advanced feed velocity of $\mathrm{v}_{\mathrm{f}}=2000 \mathrm{~mm} / \mathrm{min}$ a slight tendency towards the formation of tinsels of greater expanse on the tapered flanks of the rotary swaging dies was detected. The particle of greatest expanse found here had a projected area of $A_{\max }=7.2 \mathrm{~mm}^{2}$. Generally, the tapered flanks of the dies exhibited barely any abrasive particles after the machining procedures. Compared to the experiments conducted first, the obtained results indicate a distinct reduction of abrasive particle generation and impressively underline the capability of the novel forming dies with improved design to contribute to the development of a robust dry rotary swaging process layout. Furthermore, the findings from the experiments using the novel rotary swaging dies clearly underpin the before formulated theory of particle generation when dry rotary swaging with macro structured dies. This theory states that particle generation can be traced back to the local strain and compression induced in the surface near material layers of the work piece, occurring when the sine wave structured reduction zone and the work pieces come into contact. These processes are associated with ongoing material embrittlement and ultimately the detaching of abrasive particles from the work pieces' surfaces. The less pronounced geometry of the sine wave structures in the reduction zone of the novel functionalized rotary swaging dies allowed to distinctively cut the number of abrasive particle generated, which confirms the explained mechanism of particle generation.

\section{Conclusion}

In this work the generation of abrasive particles for dry rotary swaging with functionalized forming dies was investigated. Experiments were conducted applying uncoated and hard coated rotary swaging dies exhibiting macro structured reduction zones to the machining of 3.3206 aluminum and 1.0038 steel tubes. Due to their macro structured reduction zone such forming dies are suitable to effectively control the axial reaction force during the process. However, with regard to abrasive particle generation, this forming dies design is not sufficient for the machining of larger quantities of work pieces. Distinct amounts of abrasive particles were generated predominantly in the structured reduction zone. Particles subsequently penetrate the gaps between the rotary swaging dies, agglomerate to tinsels of greater expanse, and ultimately hinder the dies from complete closing. Alternating strain and compression induced in the surface near material layers of the work pieces while machining was identified as the abrasive particle generation mechanism. The local deformation results in a distinct strain hardening of the work piece material accompanied with ongoing local embrittlement and at last the detachment of abrasive particles from the work piece's surface. This mechanism is distinctively amplified for the machining of aluminum work pieces with uncoated rotary swaging dies due to strong adhesion accompanied with increased shearing of the surface near material layer of the work pieces. Based on the findings, forming dies of improved design were introduced, exhibiting sine wave structures of fading amplitude and DLC hard coated surfaces. This less pronounced macro structure allowed to distinctively reducing the number of abrasive particles generated in dry rotary swaging experiments. The application of such functionalized forming dies is one key step towards the successful development of robust dry rotary swaging processes accompanied with major economic and ecological benefits.

Acknowledgements: The authors would like to thank the German Research Foundation (DFG Deutsche Forschungsgemeinschaft) for funding this work within the subproject "Potentials of Dry Rotary Swaging" of the priority program SPP 1676 "Dry metal forming - sustainable production through dry processing in metal forming." The experimental assistance by Mr. Christian Rösner is greatly appreciated. 


\section{References}

1. P. Groche, F. Heislitz, Kraftbedarf beim Kaltrundkneten - Abschlussbericht zum FKMVorhaben Nr. 224, FKM-Heft 224 (2000)

2. F. Böhmermann, H. Hasselbruch, M. Herrmann, O. Riemer, A. Mehner, H.-W. Zoch, B. Kuhfuss, Trockenrundkneten - Funktionalisierte Werkzeugoberflächen für eine schmierstofffreie Prozessauslegung, wt Werkstattstechnik online 105, 11/12 (2015) 830-835

3. H. Hetzner, Systematische Entwicklung amorpher Kohlenstoffschichten unter Berücksichtigung der Anforderungen der Blechmassivumformung, Dissertation, Universität Erlangen (2014)

4. H. Hasselbruch, M. Herrmann, A. Mehner, B. Kuhfuss, Development, characterization and testing of tungsten doped DLC coatings for dry rotary swaging, MATEC Web of Conferences 21 (2015)

5. M. Herrmann, C. Schenck, B. Kuhfuss, FEM simulation of infeed rotary swaging with structured tools, MATEC Web of Conferences 21 (2015)

6. F. Böhmermann, M. Herrmann, O. Riemer, B. Kuhfuss, Abrasive Particle Generation in Dry Rotary Swaging, Dry Metal Forming OAJ 3 (2017) 001-006

7. M. Herrmann, F. Böhmermann, H. Hasselbruch, B. Kuhfuss, O. Riemer, A. Mehner, H.-W. Zoch, Forming without Lubricant - Functionalized Tool Surfaces for Dry Forming Applications, Procedia Manufacturing 8 (2017) 533-540

8. M. Herrmann, C. Schenck, B. Kuhfuss, Dry rotary swaging with structured tools, Procedia CIRP 40 (2016) 654-659

9. Y. Liu, M. Herrmann, C. Schenck, B. Kuhfuss, Plastic Deformation History in Infeed Rotary Swaging Process, AIP Conference Proceedings 1896 (2017) 080013

10. M. Herrmann, C. Schenck, B. Kuhfuss, Graded Structured Tools for Dry Rotary Swaging, Dry Metal Forming OAJ 4 (2018) 000-000 